\title{
Noseclips in children performing spirometry
}

\section{To the Editor:}

Chavasse et al. [1] evaluated the use of noseclips in children performing spirometry. They found that there was no clear benefit of using noseclips in children performing open-circuit spirometry. They also stated that their literature search found no studies addressing this issue. However, in 1997 our group published a similar study, which also showed no clear benefit with noseclips [2]. We randomised 80 adults and 81 children (59 with asthma, 12 with cystic fibrosis, and $22 \%$ with airways obstruction) to perform forced expiratory spirometry with and without noseclips. We found no significant differences between values obtained with noseclips versus without noseclips. When we performed a Medline search, using noseclips as the keyword, our study was not identified. Apparently the journal in which it was published, Respiratory Care, was not included in Medline until the year 2000. Thus, there are at least two studies rather than one that indicate that the routine use of noseclips is not necessary in children performing routine spirometry.

\section{E. Carter}

Pulmonary Division, Children's Hospital \& Regional Medical Center, Seattle, WA, USA.

\section{References}

1. Chavasse R, Johnson P, Francis J, Balfour-Lynn I, Rosenthal M, Bush A. To clip or not to clip? Noseclips for spirometry. Eur Respir J 2003; 21: 876-878.

2. Pina JS, Behrens ML, Moffitt DR, Roth BR, Carter ER. Are noseclips necessary in adults and children performing forced expiratory spirometry? Respir Care 1997; 42: 492-497.

From the authors:

I would like to thank E. Carter for his comments regarding our manuscript [1]. Unfortunately, as they accept, their previous publication [2] does not appear using standard electronic literature searches (Medline or PubMed), and hence our failure to identify their work. This only serves to confirm the fallibility of current electronic reference databases.

Our trial results are similar, however, showing no group benefit for the use of noseclips in the performance of open-circuit spirometry. Whilst this could indicate that we should abandon the use of noseclips for this procedure, we found that some children produced significantly better results using one or other technique [1]. As a consequence, several children now request to use noseclips routinely who did not before. Furthermore, we have only studied select groups of patients (i.e. those with asthma and cystic fibrosis) and therefore the results can only be extrapolated to other patient groups with care, and are likely to be inappropriate in some groups as commented on in our original manuscript. Certainly, repeated measurements by an individual should utilise the same technique each time to allow true comparison between measurement episodes.

Bearing these points in mind, the weight of evidence should now allow this information to be included in future guidelines for spirometry.

\section{R. Chavasse}

Queen Mary's Hospital for Children, Carshalton, Surrey, UK.

\section{References}

1. Chavasse R, Johnson P, Francis J, Balfour-Lynn I, Rosenthal M, Bush A. To clip or not to clip? Noseclips for spirometry. Eur Respir J 2003; 21: 876-878.

2. Pina JS, Behrens ML, Moffitt DR, Roth BR, Carter ER. Are noseclips necessary in adults and children performing forced expiratory spirometry? Respir Care 1997; 42: 492497. 